Vol 12, Issue 2, 2019

\title{
CAROTID ARTERY INTIMA-MEDIA THICKNESS AND 10-YEAR RISK OF HEART DISEASE IN DIABETIC PATIENTS: A COMPARATIVE STUDY
}

\author{
VINODKUMAR MUGADA*, RAJ KIRAN KOLAKOTA \\ Department of Pharmacy Practice, Vignan Institute of Pharmaceutical Technology, Visakhapatnam, Andhra Pradesh, India. \\ Email: mugadavinodkumar18@gmail.com
}

Received: 20 August 2018, Revised and Accepted: 28 September 2018

\begin{abstract}
Objective: The aim of the present study was to assess the factors affecting carotid artery intima-media thickness (CIMT) and 10-year risk of heart disease in diabetic patients classified according to CIMT.

Methods: This was an analytical cross-sectional study conducted on 92 patients for 1 year. 10-year risk of heart disease was calculated using the American College of Cardiology/American Heart Association Guideline on the Assessment of Cardiovascular Risk. Based on CIMT, the subjects were classified into two groups. Group 1 contains subjects with CIMT $<0.9$ and Group 2 contains subjects with CIMT $\geq 0.9$. The Mann-Whitney U-test, Pearson's correlation, and descriptive statistics were used to compare and describe the data. The level of statistical significance was taken at $\mathrm{p}<0.05$.

Results: Patients with 51-60 years of age group are high in number. Males were predominantly high than their counterparts. There is a statistically significant association between total cholesterol $(\mathrm{p}=0.001)$, high-density lipoproteins $(\mathrm{p}=0.000)$, low-density lipoproteins ( $\mathrm{p}=0.001)$, postprandial blood sugar $(\mathrm{p}=0.000)$, and hemoglobin $1 \mathrm{Ac}(\mathrm{p}=0.035)$ with CIMT. The mean 10 -year risk of heart disease in Groups 1 and 2 is $13.13 \pm 15.40$ and $23.63 \pm 17.57$, respectively. There is statistically highly significant association $(\mathrm{p}=0.000)$ of 10 -year risk of heart disease between two groups. There is a positive correlation $(\mathrm{r}=0.45, \mathrm{p}<0.0001)$ between CIMT and risk of heart disease.
\end{abstract}

Conclusion: Our study found that greater the CIMT, greater the risk of the heart of disease.

Keywords: Total cholesterol, High-density lipoproteins, Low-density lipoproteins, Blood pressure, diabetes, Carotid artery intima-media thickness.

(C) 2019 The Authors. Published by Innovare Academic Sciences Pvt Ltd. This is an open access article under the CC BY license (http://creativecommons. org/licenses/by/4. 0/) DOI: http://dx.doi.org/10.22159/ajpcr.2019.v12i2.29165

\section{INTRODUCTION}

The carotid artery intima-media thickness (CIMT) can be used as an important parameter to detect and assess atherosclerosis and for evaluating the risk of cardiovascular disease (CVD) [1,2]. In individuals with type 1 or type 2 diabetes, per $0.1 \mathrm{~mm}$ increase in common CIMT, the hazard ratio for a cardiovascular event is 1.12 (95\% confidence interval: 1.07-1.16) [3]. Values of CIMT $>0.9 \mathrm{~mm}$ are considered abnormal and values $>1 \mathrm{~mm}$ correlate with increased the incidence of atherosclerosis and cardiovascular events [4,5]. Several traditional modifiable cardiovascular risk factors including obesity, high blood pressure, high blood sugar, dyslipidemia, and cigarette smoking had been correlated with elevated CIMT by population-based studies [6]. A study showed higher values for atherogenic factors such as age, body mass index (BMI), systolic and diastolic blood pressure, and lowdensity lipoproteins (LDL) with respect to thickness [7]. CIMT has been independently associated with coronary artery disease in Indian subjects [8]. Another study reported that increased CIMT determines the risk of future coronary heart disease and stroke [9]. Therefore, predicting CIMT can be used for diagnosing premature CVD.

The aim of the present study was to know the association of CIMT and 10 -year risk of heart disease in diabetic patients.

\section{METHODS}

\section{Study design}

The information about CIMT and risk of heart disease was observed at the same time. There is no need to follow-up. The subjects were categorized into two groups based on CIMT. The factors affecting CIMT and risk of heart disease were compared between two groups. The features of our study best suit with analytical and comparative cross- sectional study. Hence, our study design was analytical and comparative cross-sectional study.

\section{Ethical approval}

Our study was approved by the Institutional Ethical Committee (RKHEC/RC NO. Clinicals/Pharm.D/N2/2017, Dt 03/05/2017). The objective of the study was clearly explained to the patient and a patient consent form was obtained.

\section{Study duration}

This study was conducted on 92 diabetic patient's Inpatient Department of Medicine, RK Hospital, Gajuwaka, for 10 months, that is, from May 5, 2017 to February 28, 2018.

\section{Participants}

- Patients with the age group between 40 and 70 years, patients with diabetes alone and diabetes along with hypertension and dyslipidemia were included in the study.

- Patience with the age group of $<40$ and $>70$ years, critically ill patients were excluded from the study.

\section{Sampling technique and sample size}

Stratified random sampling (disproportionate) was used to select the diabetic patients. The patients were classified into two groups based on CIMT. The sample size was estimated from Raosoft Inc., sample size calculator. The sample size was 92 . Group $1(n=37)$ contains subjects with CIMT $<0.9$, whereas Group $2(n=55)$ contains subjects with CIMT $\geq 0.9$.

Data analysis

A prestructured data collection form was prepared to obtain demographic and clinical data from the patient. The data regarding 
CIMT were obtained from laboratory reports. The 10 -year risk of heart disease was calculated using guidelines form the American College of Cardiology/American Heart Association on assessment of cardiovascular risk. The 10-year risk of heart disease was represented in percentage. Descriptive statistics were calculated for quantitative data such as age, total cholesterol (TC), and systolic blood pressure. Frequency and percentage were calculated for qualitative data. Data were represented in tables to compare and contrast between the two groups. The normality of numerical data was tested using the ShapiroWilk test. Independent t-test is used for numerical data when the normality of data confirms normal distribution. Non-parametric tests like Mann-Whitney U-Test were used wherever applicable. Pearson's correlation coefficient test was used to find the correlation between two variables. The level of significance was considered at $p<0.05$. If the level of significance was $\mathrm{p}<0.01$, then it was considered statistically highly significant.

\section{RESULTS}

As shown in Table 1, 51-60 years age group was high in number in both groups. Males are predominantly higher than females in both the groups. The percentage of hypertensives, dyslipidemic patients, and non-smokers is high in the number in both the groups. The prevalence of the absence of cerebrovascular accident and coronary artery disease was high in both the groups. The proportion of non-alcoholics and nonsmokers was high in both groups.

There was a statistically highly significant relation between TC $(\mathrm{p}=0.001)$, high-density lipoproteins (HDL) $(\mathrm{p}=0.000), \mathrm{LDL}(\mathrm{p}=0.001)$, postprandial blood sugar (PPBS) $(p=0.000)$, BMI $(p=0.007)$, age $(\mathrm{p}=0.008), 10$-year risk of heart disease $(\mathrm{p}=0.000)$, waist-hip ratio (WHR) $(\mathrm{p}=0.001), \mathrm{LDL} / \mathrm{HDL}$ ratio $(<0.0001)$, and $\mathrm{TC} / \mathrm{HDL}$ ratio $(<0.0001)$ with CIMT. Hemoglobin (HB) $1 \mathrm{Ac}(\mathrm{p}=0.035)$ had statistically significant association with CIMT.

As shown in Table 2, CIMT was having statistically highly significant correlation with age $(p=0.000)$, HDL $(p=0.000)$, LDL $(p=0.007)$, SBP $(p=0.005), \operatorname{PPBS}(p=0.006)$, WHR $(p=0.002)$, LDL/HDL ratio $(p=0.000)$,
TC/HDL ratio $(\mathrm{p}<0.0001)$, duration of diabetes $(\mathrm{p}<0.0001)$, and 10year risk of heart disease $(\mathrm{p}<0.0001)$. TC and Hb1Ac found to have statistically significant correlation $(\mathrm{p}=0.011$ and $\mathrm{p}=0.038$, respectively).

\section{DISCUSSION}

As shown in Table 1, 51-60 years age group patients were predominantly high. There was a statistically significant association between age and CIMT $(p=0.004)$. Males were higher than their counterparts. Non-smokers were high in number and dyslipidemia was high in both groups. Tripathy et al. reported a high prevalence of diabetes in patients aged 25-44 years [10]. A statistically significant difference was reported in age difference by Bharati et al., the prevalence of diabetes is higher in the age group of $\geq 50$ years than in persons aged between 20 and 49 years [11]. Diabetes in India was rising and women are more affected than males [12]. Bharati et al. [11] also reported a high prevalence of diabetes mellitus in females. Non-alcoholics are high in both the groups. The percentage of non-hypertensive patients, the percentage of patients with the absence of cerebrovascular accident and coronary artery disease was high. Duration of diabetes was significantly correlated $(\mathrm{p}<0.001)$ with CIMT in our study. It may suggest an increase in the risk of CVD in patients. However, Mounika et al. [13] reported a 36\% of the onset of renal and cardiac complications in patients with 1-5 years of the duration of diabetes, whereas $31.6 \%$ of the onset of renal and cardiac complications in patients with 6-10 years of duration.

The mean blood lipid profile values of Group 1 are higher than Group 2 as shown in Table 3 . There was a statistically highly significant association between TC, HDL, LDL, LDL/HDL ratio, and TC/HDL ratio, with CIMT, wherein triglycerides did not show any statistically significant association with CIMT in our study (Table 1). Similar associations were reported by Yang et al. [14]; however, triglycerides and TC did not show any significant association in his study. He observed a close correlation between CIMT and LDL/HDL cholesterol ratio than LDL cholesterol levels even after the adjustment of age. Furthermore, LDL/HDL cholesterol ratio showed a positive association with the prevalence of carotid plaques.

Table 1: Sociodemographic and clinical characteristics of patients

\begin{tabular}{|c|c|c|c|c|}
\hline \multirow[t]{2}{*}{ S. No. } & \multirow[t]{2}{*}{ Characteristic } & \multirow{2}{*}{$\begin{array}{l}\text { Group } 1(n=37) \\
\text { Frequency }(\%)\end{array}$} & \multirow{2}{*}{$\begin{array}{l}\text { Group } 2(n=55) \\
\text { Frequency }(\%)\end{array}$} & \multirow[t]{2}{*}{ p value } \\
\hline & & & & \\
\hline \multirow[t]{4}{*}{1} & Age in years & & & \\
\hline & $51-60$ & $15(40.54)$ & $24(43.63)$ & \\
\hline & $61-70$ & $5(13.51)$ & $15(27.30)$ & \\
\hline & $71-80$ & $3(8.10)$ & $9(16.36)$ & \\
\hline \multirow[t]{3}{*}{2} & Gender & & & \\
\hline & Females & $12(32.43)$ & $23(41.82)$ & 0.109 \\
\hline & Males & $25(67.57)$ & $32(51.18)$ & \\
\hline \multirow[t]{3}{*}{3} & Alcoholism & & & \\
\hline & Alcoholic & $6(16.22)$ & $12(21.81)$ & 0.506 \\
\hline & Non-alcoholic & 31 (83.78) & $43(71.18)$ & \\
\hline \multirow[t]{3}{*}{4} & Hypertension & & & \\
\hline & Non-hypertensive & $7(18.91)$ & $19(34.55)$ & 0.102 \\
\hline & Hypertensive & 30 (81.09) & $36(65.45)$ & \\
\hline \multirow[t]{2}{*}{5} & Cerebrovascular accident & & & \\
\hline & Absent & 30 (81.09) & $35(63.6)$ & \\
\hline \multirow[t]{3}{*}{6} & Coronary artery disease & & & \\
\hline & Present & $6(16.22)$ & $11(20)$ & 0.646 \\
\hline & Absent & 31 (83.78) & $44(80)$ & \\
\hline \multirow[t]{3}{*}{7} & Dyslipidemia & & & \\
\hline & Present & $21(56.76)$ & $47(85.5)$ & 0.002 \\
\hline & Absent & $16(43.24)$ & $8(14.5)$ & \\
\hline \multirow[t]{3}{*}{8} & Smoking & & & \\
\hline & Smokers & $7(18.91)$ & $14(25.45)$ & 0.461 \\
\hline & Non-smokers & 30 (81.09) & $41(74.55)$ & \\
\hline
\end{tabular}

*Mann-Whitney U-test 
Our study reported a statistically significant association between BMI, WHR, and HbA1c levels. In contrast, Yang et al. reported no significant difference with these parameters. The combined application of LDL cholesterol and HDL cholesterol was superior to separate lipid parameters for assessing the risk of early-stage atherosclerosis in apparently healthy people from the general population [14]. Enomoto et al. [15] found a significant association between IMT and

Table 2: Correlation analysis of demographic and clinical variables with CIMT

\begin{tabular}{lllll}
\hline S. No. & Parameter & r value & $\mathbf{9 5 \%}$ CI & p value \\
\hline 1 & TC & 0.26 & $0.06-0.44$ & 0.011 \\
2 & HDL & -0.34 & $-0.51-0.14$ & 0.000 \\
3 & LDL & 0.28 & $0.07-0.45$ & 0.007 \\
4 & TG & 0.07 & $-0.13-0.27$ & 0.512 \\
5 & SBP & 0.29 & $0.09-0.46$ & 0.005 \\
6 & DBP & 0.09 & $-0.11-0.28$ & 0.407 \\
7 & FBS & 0.16 & $-0.04-0.35$ & 0.129 \\
8 & PPBS & 0.28 & $0.08-0.45$ & 0.006 \\
9 & HbA1c & 0.22 & $0.01-0.40$ & 0.038 \\
10 & Age & 0.34 & $0.14-0.50$ & 0.000 \\
11 & Duration of diabetes & 0.40 & $0.21-0.56$ & $<0.0001$ \\
12 & 10-year risk of heart & 0.45 & $0.27-0.60$ & $<0.0001$ \\
& disease & & & \\
13 & BMI & 0.16 & $-0.04-0.35$ & 0.121 \\
14 & WHR & 0.15 & $0.09-0.24$ & 0.002 \\
15 & LDL/HDL ratio & 0.36 & $0.17-0.53$ & 0.000 \\
16 & TC/HDL ratio & 0.49 & $0.31-0.63$ & $<0.0001$ \\
\hline
\end{tabular}

CIMT: Carotid artery intima-media thickness, $\mathrm{CI}$ : Confidence interval, HDL: High-density lipoproteins, TC: Total cholesterol, LDL: Low-density lipoproteins, TGs: Triglycerides, SBP: Systolic blood pressure, DBP: Diastolic blood pressure, FBS: Fasting blood sugar, PPBS: Postprandial blood sugar, HB: Hemoglobin, BMI: Body mass index, WHR: Waist-hip ratio proatherogenic lipoprotein measurements, and it was reported that the LDL/HDL ratio was found to be the strongest predictor for IMT progression. Some studies suggested that cholesterol ratios can better predict the risk of CVD than individual lipid profile parameters [16-20]. Katakami et al. [21] observed that cholesterol ratios can be good risk indicators for early-stage atherosclerosis, even if the conventional lipid parameters are within normal range.

Our study found a statistically significant association between BMI and CIMT. Some studies reported a significant association between BMI and CIMT $[9,22,23]$. Ozdemir et al. [24] did not find a correlation between BMI and CIMT when comparing participants with normal BMI to overweight subjects. One study reported an increase of one BMI unit caused a $0.009 \mathrm{~mm}$ increase in CIMT and an increase of 1 year in age caused a $0.011 \mathrm{~mm}$ increase in CIMT in their study [23]. Butt et al. [25] reported that overweight patients significantly took dominance in a low-risk category and he did not found a significant correlation between HDL, LDL, TC, TG, and BMI.

Systolic blood pressure was having a statistically significant correlation with CIMT ( $\mathrm{p}=0.005)$ in our study. Norbert et al. [26] reported that the mean CIMT of newly diagnosed hypertensives was significantly higher than the mean CIMT values of the drug-treated hypertensives. Hong et al. [27] reported higher CIMT values in prehypertensives than normotensives. Bashir et al. [28] reported a strong positive correlation of CIMT with systolic blood pressure $(\mathrm{p}=0.000)$ and a moderately positive correlation with diastolic blood pressure.

There is a highly significant correlation of CIMT with duration of diabetes $(\mathrm{p}<0.0001)$ in our study. Bashir et al. [28] reported a highly significant correlation of CIMT with duration of diabetes $(p=0.000)$. The strong relationship between CIMT with duration of diabetes reflects the detrimental effect on arterial wall thickening through ongoing

Table 3: Association of variables of patients with CIMT

\begin{tabular}{|c|c|c|c|c|}
\hline S. No. & Parameter & Group $1(n=37)$ & Group $2(n=55)$ & p value \\
\hline 1 & $\mathrm{TC}$ & $\begin{array}{l}195.3 \pm 44.87 \mathrm{mg} / \mathrm{dL} \\
(95 \% \mathrm{CI}: 181.7-209.0)\end{array}$ & $\begin{array}{l}222.8 \pm 40.57 \mathrm{mg} / \mathrm{dL} \\
(95 \% \mathrm{CI}: 211.9-233.6)\end{array}$ & $0.001^{*}$ \\
\hline 2 & HDL & $\begin{array}{l}49.13 \pm 7.63 \mathrm{mg} / \mathrm{dL} \\
(95 \% \mathrm{CI}: 45.55-50.27)\end{array}$ & $\begin{array}{l}41.58 \pm 8.68 \mathrm{mg} / \mathrm{dL} \\
(95 \% \mathrm{CI}: 39.26-43.92)\end{array}$ & 0.000 \\
\hline 3 & LDL & $\begin{array}{l}123.59 \pm 34.35 \mathrm{mg} / \mathrm{dL} \\
(95 \% \mathrm{CI}: 108.3-128.9)\end{array}$ & $\begin{array}{l}139.29 \pm 30.67 \mathrm{mg} / \mathrm{dL} \\
(95 \% \mathrm{CI}: 130.2-146.8)\end{array}$ & 0.001 \\
\hline 4 & Triglycerides & $\begin{array}{l}156.9 \pm 69.86 \\
(95 \% \text { CI: } 133.6-180.2)\end{array}$ & $\begin{array}{l}185.7 \pm 99.05 \\
(95 \% \text { CI: } 159.0-212.5)\end{array}$ & 0.108 \\
\hline 5 & LDL/HDL ratio & $\begin{array}{l}2.49 \pm 0.65 \\
(95 \% \text { CI: } 2.28-2.71)\end{array}$ & $\begin{array}{l}3.27 \pm 1.02 \\
(95 \% \text { CI: } 2.99-3.55)\end{array}$ & $<0.0001^{*}$ \\
\hline 6 & $\mathrm{TC} /$ HDL ratio & $\begin{array}{l}4.11 \pm 0.80 \\
(95 \% \text { CI: } 3.84-4.38)\end{array}$ & $\begin{array}{l}5.53 \pm 1.31 \\
(95 \% \text { CI: } 5.17-5.88)\end{array}$ & $<0.0001^{*}$ \\
\hline 7 & Systolic blood pressure & $\begin{array}{l}130 \pm 15.27 \mathrm{mmHg} \\
(95 \% \mathrm{CI}: 124.9-135.1)\end{array}$ & $\begin{array}{l}135.63 \pm 16.64 \mathrm{mmHg} \\
(95 \% \mathrm{CI}: 131.1-140.1)\end{array}$ & 0.081 \\
\hline 8 & Diastolic blood pressure & $\begin{array}{l}84.32 \pm 5.02 \mathrm{mmHg} \\
(95 \% \text { CI: } 82.65-86.00)\end{array}$ & $\begin{array}{l}82.16 \pm 11.12 \mathrm{mmHg} \\
(95 \% \mathrm{CI}: 79.16-85.17)\end{array}$ & 0.401 \\
\hline 10 & PPBS & $\begin{array}{l}216.1 \pm 59.73 \mathrm{mg} / \mathrm{dL} \\
(95 \% \text { CI: } 197.9-234.3)\end{array}$ & $\begin{array}{l}276.4 \pm 92.46 \mathrm{mg} / \mathrm{dL} \\
(95 \% \mathrm{CI}: 251.7-301.2)\end{array}$ & $0.000^{*}$ \\
\hline 11 & $\mathrm{HbA1c}$ & $\begin{array}{l}7.268 \pm 0.675 \\
(95 \% \text { CI: } 7.06-7.47)\end{array}$ & $\begin{array}{l}7.691 \pm 1.077 \\
(95 \% \text { CI: } 7.40-7.97)\end{array}$ & 0.035 \\
\hline 12 & 10-year risk of heart disease & $\begin{array}{l}13.13 \pm 15.40 \\
(95 \% \text { CI: } 7.99-18.26)\end{array}$ & $\begin{array}{l}23.63 \pm 17.57 \\
(95 \% \text { CI: } 18.88-28.38)\end{array}$ & $0.000^{*}$ \\
\hline 13 & BMI & $\begin{array}{l}22.76 \pm 3.64 \\
(95 \% \text { CI: } 21.55-23.97)\end{array}$ & $\begin{array}{l}25.42 \pm 4.59 \\
(95 \% \text { CI: } 24.18-26.66)\end{array}$ & 0.007 \\
\hline 14 & WHR & $\begin{array}{l}0.87 \pm 0.06 \\
(95 \% \text { CI: } 0.85-0.89)\end{array}$ & $\begin{array}{l}0.93 \pm 0.11 \\
(95 \% \text { CI: } 0.90-0.95)\end{array}$ & 0.001 \\
\hline 15 & Duration of diabetes & $\begin{array}{l}7.83 \pm 5.08 \\
(95 \% \text { CI: } 6.14-9.53)\end{array}$ & $\begin{array}{l}9.34 \pm 4.92 \\
(95 \% \text { CI: } 8.01-10.6)\end{array}$ & 0.140 \\
\hline
\end{tabular}

*Independent t-test. CIMT: Carotid artery intima-media thickness, TC: Total cholesterol, HDL: High-density lipoproteins, LDL: Low-density lipoproteins, FBS: Fasting blood sugar, PPBS: Postprandial blood sugar, HB: Hemoglobin, BMI: Body mass index, WHR: Waist-hip ratio 
atherosclerotic events. In our study, PPBS levels and Hb1Ac levels have significant association and correlation with CIMT (Tables 2 and 3). One study reported no significant association of CIMT with Hb1Ac levels [28]. Few studies reported that blood pressure control was more important for all the endpoints, especially cardiovascular complications in diabetic patients as compared to the glycemic control $[29,30]$

In our study, the 10-year risk of heart disease was statistically highly significant association and correlation with CIMT. IMT measurements could help in predicting the risk of CVD because thickening of arteries is a known hallmark feature of atherosclerosis. Several studies have shown this association between CIMT and risk of CVD in future. However, recommendations regarding the use of CIMT for predicting the risk of CVD events are conflicting. Lorenz et al. [31] found an increase in relative risks of CVD events by a factor of 1.15 for every $0.1-\mathrm{mm}$ increase in CIMT. In contrast, den Ruijter et al. [3] found no meaningful addition to CVD event prediction when CIMT was added to conventional risk prediction models. However, many other studies showed an increase in the risk of CVD events with an increase in CIMT [7,32,33].

\section{CONCLUSION}

Age, duration of diabetes, TC, LDL, HDL, LDL/HDL ratio, TC/HDL ratio, PPBS levels, Hb1Ac levels, systolic blood pressure, and WHR affect the CIMT. The risk of heart disease increases with increase in the CIMT.

\section{AUTHORS' CONTRIBUTION}

Vinodkumar Mugada - concept, design, literature search, data acquisition, manuscript preparation, and editing. Raj Kiran Kolakota - concept, design, the definition of intellectual content, and review.

\section{CONFLICTS OF INTEREST}

The authors declared that they have no conflicts of interest.

\section{REFERENCES}

1. Kablak-Ziembicka A, Przewlocki T, Tracz W, Pieniazek P, Musialek P, Stopa I, et al. Diagnostic value of carotid intima-media thickness in indicating multi-level atherosclerosis. Atherosclerosis 2007;193:395-400.

2. Filippo M, Jasjit SS, Chirinjeev K. Atherosclerosis Disease Management. Berlin: Springer; 2010.

3. den Ruijter HM, Peters SA, Groenewegen KA, Anderson TJ, Britton AR, Dekker JM, et al. Common carotid intima-media thickness does not add to Framingham risk score in individuals with diabetes mellitus: The USE-IMT initiative. Diabetologia 2013;56:1494-502.

4. Wikstrand J, Wendelhag I. Methodological considerations of ultrasound investigation of intima-media thickness and lumen diameter. J Intern Med 1994;236:555-9.

5. Simon A, Gariepy J, Chironi G, Megnien JL, Levenson J. Intima-media thickness: A new tool for diagnosis and treatment of cardiovascular risk. J Hypertens 2002;20:159-69.

6. Rundek T, Blanton SH, Bartels S, Dong C, Raval A, Demmer RT, et al. Traditional risk factors are not major contributors to the variance in carotid intima-media thickness. Stroke 2013;44:2101-8.

7. Chambless LE, Heiss G, Folsom AR, Rosamond W, Szklo M, Sharrett AR, et al. Association of coronary heart disease incidence with carotid arterial wall thickness and major risk factors: The atherosclerosis risk in communities (ARIC) study, 1987-1993. Am J Epidemiol 1997;146:483-94.

8. Jadhav UM, Kadam NN. Carotid intima-media thickness as an independent predictor of coronary artery disease. Indian Heart J 2001;53:458-62.

9. Chambless LE, Folsom AR, Davis V, Sharrett R, Heiss G, Sorlie P, et al. Risk factors for progression of common carotid atherosclerosis: The atherosclerosis risk in communities study, 1987-1998. Am J Epidemiol 2002;155:38-47.

10. Tripathy JP, Thakur JS, Jeet G, Chawla S, Jain S, Pal A, et al. Prevalence and risk factors of diabetes in a large community-based study in North India: Results from a STEPS survey in Punjab, India. Diabetol Metab Syndr 2017;9:8.

11. Bharati DR, Pal R, Kar S, Rekha R, Yamuna TV, Basu M, et al.
Prevalence and determinants of diabetes mellitus in Puducherry, South India. J Pharm Bioallied Sci 2011;3:513-8

12. Diabetes in India Rising, with Women at a Particular Disadvantage. The Guardian; 2018. Available from: https://www.theguardian.com/globaldevelopment/2013/may/24/diabetes-India-women-disadvantage. [Last cited on 2016 Apr 20].

13. Mounika S, Keerthy V, Ramadasu P, Shankar SB, Lakshmi CH. Prevalence of acute cardiac and renal complications in poorly controlled diabetics and role of clinical pharmacist in modifying disease outcome in a tertiary care hospital. Int J Pharm Pharm Sci 2015;7:192-6.

14. Yang C, Sun Z, Li Y, Ai J, Sun Q, Tian Y, et al. The correlation between serum lipid profile with carotid intima-media thickness and plaque. BMC Cardiovasc Disord 2014;14:181.

15. Enomoto M, Adachi H, Hirai Y, Fukami A, Satoh A, Otsuka M, et al. LDL-C/HDL-C ratio predicts carotid intima-media thickness progression better than HDL-C or LDL-C alone. J Lipids 2011;2011:549137.

16. Kinosian B, Glick H, Garland G. Cholesterol and coronary heart disease: Predicting risks by levels and ratios. Ann Intern Med 1994;121:641-7.

17. Hsia SH, Pan D, Berookim P, Lee ML. A population-based, crosssectional comparison of lipid-related indexes for symptoms of atherosclerotic disease. Am J Cardiol 2006;98:1047-52.

18. Barter P, Gotto AM, LaRosa JC, Maroni J, Szarek M, Grundy SM, et al. HDL cholesterol, very low levels of LDL cholesterol, and cardiovascular events. N Engl J Med 2007;357:1301-10.

19. Ingelsson E, Schaefer EJ, Contois JH, McNamara JR, Sullivan L, Keyes MJ, et al. Clinical utility of different lipid measures for prediction of coronary heart disease in men and women. JAMA 2007;298:776-85.

20. Kastelein JJ, van der Steeg WA, Holme I, Gaffney M, Cater NB, Barter P, et al. Lipids, apolipoproteins, and their ratios in relation to cardiovascular events with statin treatment. Circulation 2008;117:3002-9.

21. Katakami N, Kaneto H, Osonoi T, Saitou M, Takahara M, Sakamoto F, et al. Usefulness of lipoprotein ratios in assessing carotid atherosclerosis in Japanese type 2 diabetic patients. Atherosclerosis 2011;214:442-7.

22. Li S, Chen W, Srinivasan SR, Bond MG, Tang R, Urbina EM, et al. Childhood cardiovascular risk factors and carotid vascular changes in adulthood: The Bogalusa heart study. JAMA 2003;290:2271-6.

23. Rashid SA, Mahmud SA. Correlation between carotid artery intimamedia thickness and luminal diameter with body mass index and other cardiovascular risk factors in adults. Sultan Qaboos Univ Med J 2015; $15:$ e344-50.

24. Ozdemir H, Artaş H, Serhatlioğlu S, Oğur E. Effects of overweight on luminal diameter, flow velocity and intima-media thickness of carotid arteries. Diagn Interv Radiol 2006;12:142-6.

25. Butt M, Ali AM, Bakry MM. Lipid profile patterns and association between glycated haemoglobin $(\mathrm{HbA} 1 \mathrm{C})$ and atherogenic index of plasma (AIP) in diabetes patients at a tertiary care hospital in Malaysia. Int J Pharm Pharm Sci 2017;9:150-4.

26. Norbert NU, Blessing CU, Maclean RA. Serum lipid profile and its relationship with carotid intima-media thickness in hypertensive adults attending a tertiary hospital in Southern Nigeria. Am J Med Med Sci 2017;7:202-9.

27. Hong H, Wang H, Liao H. Prehypertension is associated with increased carotid atherosclerotic plaque in the community population of Southern China. BMC Cardiovasc Disord 2013;13:20.

28. Bashir F, Nageen A, Kidwai S, Ara J. Carotid intima-media thickness and cardio metabolic risk factors in Pakistani Type 2 diabetics. Saudi J Health Sci 2017;6:145.

29. Du HW, Li JY, He Y. Glycemic and blood pressure control in older patients with hypertension and diabetes: Association with carotid atherosclerosis. J Geriatr Cardiol 2011;8:24-30.

30. Olt S, Sirik M, Baykan AH, Celiker M. The relationship between $\mathrm{HbAlc}$ and carotid intima-media thickness in Type 2 diabetic patients. Pan Afr Med J 2016;23:22

31. Lorenz MW, Markus HS, Bots ML, Rosvall M, Sitzer M. Prediction of clinical cardiovascular events with carotid intima-media thickness: A systematic review and meta-analysis. Circulation 2007;115:459-67.

32. Lorenz MW, Schaefer C, Steinmetz H, Sitzer M. Is carotid intima media thickness useful for individual prediction of cardiovascular risk? Tenyear results from the carotid atherosclerosis progression study (CAPS). Eur Heart J 2010;31:2041-8.

33. Rosvall M, Janzon L, Berglund G, Engström G, Hedblad B. Incident coronary events and case fatality in relation to common carotid intimamedia thickness. J Intern Med 2005;257:430-7. 